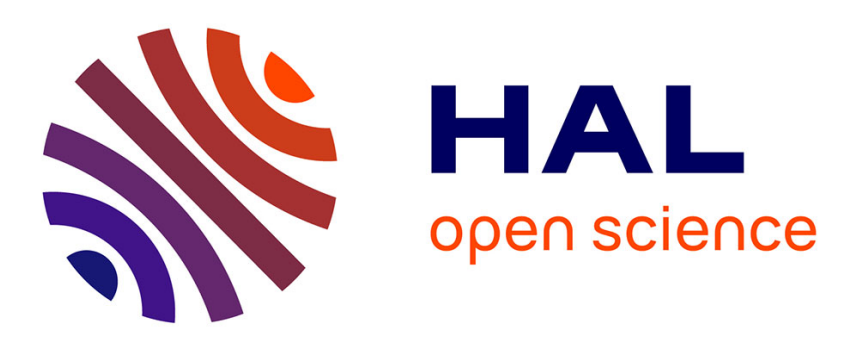

\title{
Development and evaluation of the lifestyle intervention "Obeldicks light" for overweight children and adolescents
}

\author{
Thomas Reinehr, Anke Schaefer, Katrin Winkel, Emily Finne, Petra Kolip
}

\section{To cite this version:}

Thomas Reinehr, Anke Schaefer, Katrin Winkel, Emily Finne, Petra Kolip. Development and evaluation of the lifestyle intervention "Obeldicks light" for overweight children and adolescents. Journal of Public Health, 2011, 19 (4), pp.377-384. 10.1007/s10389-011-0410-x . hal-00627934

\section{HAL Id: hal-00627934 \\ https://hal.science/hal-00627934}

Submitted on 30 Sep 2011

HAL is a multi-disciplinary open access archive for the deposit and dissemination of scientific research documents, whether they are published or not. The documents may come from teaching and research institutions in France or abroad, or from public or private research centers.
L'archive ouverte pluridisciplinaire HAL, est destinée au dépôt et à la diffusion de documents scientifiques de niveau recherche, publiés ou non, émanant des établissements d'enseignement et de recherche français ou étrangers, des laboratoires publics ou privés. 


\section{Development and evaluation}

\section{of the lifestyle intervention "Obeldicks light" for overweight children and adolescents}

Thomas Reinehr ${ }^{1}$, Anke Schaefer ${ }^{1}$, Katrin Winkel ${ }^{1}$, Emily Finne ${ }^{2}$, Petra Kolip ${ }^{2}$

1: Department of Paediatric Endocrinology, Diabetes and Nutrition Medicine, Vestische Youth Hospital, University of Witten/Herdecke, Dr. F. Steiner Str. 5, 45711 Datteln, Germany 2: Faculty of Health Sciences, University of Bielefeld, Postfach 100131 33501 Bielefeld, Germany

Corresponding author and address for reprint requests:

Prof. Dr. Thomas Reinehr

Department of Pediatric Endocrinology, Diabetes and Nutrition Medicine

Vestische Hospital for Children and Adolescents Datteln

University of Witten/Herdecke

Dr. F. Steiner Str. 5

D- 45711 Datteln

Germany

Tel: ++49-2363-975-229

Fax: ++49-2363-975-218

Email: T.Reinehr@kinderklinik-datteln.de

This study is registered at clinicaltrials.gov (NCT00422916). 


\section{Abstract}

2Aim:

3Specific interventions for overweight but not obese children have not been established yet. 4Therefore we developed the methods, materials, and an evaluation protocol of a lifestyle 5intervention for overweight children based on an intervention for obese children.

\section{Subjects and Methods:}

7The one-year lifestyle intervention "Obeldicks" for obese children compromised of 8physical activity, nutrition education, and behaviour counselling including an individual 9psychological care for both children and their parents was shortened reducing the amount 10of exercise training and individual counselling about $50 \%$ to a six-month intervention 11(“'Obeldicks light”).

\section{Results:}

13The evaluation protocol was based on guidelines and validated instruments with available $14 \mathrm{German}$ healthy normal-weight controls. As ideal study design a multi-centre randomized 15 controlled trail with the primary outcome change of weight status was identified. As 16secondary outcomes improvement of body composition (skinfold thicknesses; 17bioimpedance analyses), cardiovascular risk factors (blood pressure; waist circumference), 18 quality of life, dietary habits, eating, exercise, and sedentary behaviour were established. 19Potential influencing factors for treatment success were identified such as parental BMI, 20ethnicity, and socioeconomic status. All proposed instruments were validated in the 21 German representative KiGGS and DONALD study.

22Conclusions: Adapting a well-established program for obese children to overweight 23 children is an easy way to create a lifestyle intervention for overweight children. Our study 24protocol using instruments validated in German normal weight cohorts allows evaluating 25 this new intervention.

\section{6}

27Key words: lifestyle intervention, overweight, children, adolescents, randomized28controlled-trial, evaluation 


\section{Introduction}

33Overweight and obesity in childhood and adolescence is increasing world-wide (Ebbeling 34et al. 2002). Since overweight children tend to become obese adults and overweight affects 35both the children's health and their social integration (Ebbeling et al. 2002), effective 36treatments are needed. Overweight and its associated comorbidities such as hypertension, 37dyslipidemia, and disturbed glucose metabolism -which appear also frequently in children 38(I'Allemand et al. 2008; Reinehr et al. 2005a) - are likely associated with morbidity and 39premature death (Baker et al. 2007;Biro \& Wien 2010). A large epidemiological study 40demonstrated the association between body-mass index (BMI) in childhood (7 through 13 41years of age) and coronary heart disease (CHD) in adulthood (25 years of age or older) in a 42cohort of $>270,000$ Danish (Baker et al. 2007).

43Guidelines recommend long-term outpatient training programs consisting of a combination 44of physical exercise, nutrition education, and behaviour counselling for obese children and 45adolescents, but only few programs have run and have been evaluated in the past (Oude et 46al. 2009;Monasta et al. 2010). A recent Cochrane review (Oude et al. 2009) concerning 47 treatment in already obese children including 64 randomized controlled trials (RCTs) with 485,230 participants identified lifestyle interventions for obese children focused on physical 49activity and sedentary behavior in 12 studies, diet in 6 studies, and 36 concentrated on 50behaviorally orientated treatment programs. The studies included varied greatly in 51 intervention design, outcome measurements and methodological quality. Meta-analysis 52indicated a reduction in weight at 6 and 12 months follow up in lifestyle interventions. 53 While there is limited quality data to recommend one treatment program to be favored over 54another, this review shows that combined behavioral lifestyle interventions compared to 55 standard care or self-help can produce a significant and clinically meaningful weight 56reduction in obese children and adolescents.

57However, all RCTs have focused on obese children so far and even less is known about 58intervention effects in overweight children (Monasta et al. 2010; Oude et al. 2009). 59Probably, similar positive effects as in obese children can be reached in overweight 60children with less treatment intensity. Furthermore, the findings from interventions in 61obese children cannot be directly transferred to overweight children, since degree of 62overweight may influence the outcome. For example, lower weight may be associated with 63 lower awareness of weight problems or less treatment motivation. 
64In this paper, we describe the development of a lifestyle intervention as well as the 65 evaluation design to prove the effectiveness of this intervention in overweight children and 66adolescents.

\section{Subjects/Methods}

\section{Development of the intervention "Obeldicks light"}

69The lifestyle intervention for overweight children and adolescents (called "Obeldicks 70light") was developed based on the experiences of the well-established "Obeldicks" 71 intervention for obese children and adolescents. The name "Obeldicks" is adapted from the 72popular French obese comic figure "Obelix". This figure was chosen since it is associated 73 with positive qualities such as strength.

\section{Lifestyle intervention "Obeldicks"}

75The complete material and the exact description of the one-year lifestyle intervention 76"Obeldicks" is available as a training book (Reinehr et al. 2010a). Briefly, this intervention 77 is based on physical activity, nutrition education, and behaviour counselling including 78individual psychological care of the child and his/her family (see figure 1). Inclusion 79 criteria are obesity $\left(\mathrm{BMI}>97^{\text {th }}\right.$ percentile (Kromeyer-Hauschild K et al. 2001)), age 8 to 8016 years, apparently healthy and not on any medication, as well as attending regular 81school. An interdisciplinary team of paediatricians, diet-assistants, psychologists, and 82exercise physiologists is responsible for the training. Children older than 10 years are 83 separated into gender-specific intervention groups, while younger boys and girls received 84the intervention together.

85The lifestyle intervention "Obeldicks" for obese children and adolescents led to a reduction 86of overweight in $70 \%$ of the more than 1000 participants and even four years after end of 87intervention the weight reduction was sustained (Reinehr et al. 2010b). Furthermore, the 88reduction of weight was associated with an improvement of cardiovascular risk factors 89 such as hypertension, dyslipidemia, disturbed glucose metabolism, and metabolic 90syndrome not only at the end of intervention but also one year after end of intervention 91(Reinehr et al. 2006). Additionally, this lifestyle intervention led to a reduction of carotid 92intima-media thickness (Wunsch et al. 2006), a predictive factor for atherosclerosis, heart 93attack, and stroke (Lorenz et al. 2007). Finally, the weight loss was also associated with an 94improvement of quality of life in the participants suggesting a clinical relevance not only 95 from the medical point of view but also from the participants' point of view (Reinehr et al. 962005b). According to these promising results we decided to adopt this effective lifestyle 
97intervention to overweight but not obese $\left(\mathrm{BMI}>90^{\text {th }}<97^{\text {th }}\right.$ percentile (Kromeyer-Hauschild $98 \mathrm{~K}$ et al. 2001)) children and called this new type of intervention "Obeldicks light".

99

100Lifestyle intervention "Obeldicks light"

101Since the children were only overweight and not obese, the intervention was shortened 102 from 1 year (“Obeldicks") to 6 months (“Obeldicks light"). Compared to "Obeldicks", the 103 amount of physical activity training and the time- and cost-intensive individual counselling 104 were reduced about 50\%. We chose the same inclusion criteria as for "Obeldicks". The 105differences between "Obeldicks" and "Obeldicks light" are demonstrated in figure 1. In 106"Obeldicks light", the same training material as in "Obeldicks" (Reinehr et al. 2010a) are 107used.

\section{8-please insert figure 1 here-}

109Since in the lifestyle intervention "Obeldicks" the material in the nutrition and eating 110 behaviour course as well as the sport games are age- and gender- specific for children $>10$ 111years (Reinehr et al. 2010a), children and adolescents older than 10 years are divided into 112groups according to their sex and age while younger boys and girls received the 113intervention together.

114The intervention team covers many disciplines and consists of paediatricians, diet115 assistants, psychologists, and exercise physiologists trained in the methods of "Obeldicks". 116All therapists have to build up a therapeutic alliance with the children and their families. 117They have to involve family members, adopt a non-blaming position, assume motivation, 118 focus on small changes, identify the resources of the family, and create a positive climate 119 by reframing (for details see (Flodmark 2005)).

120The exercise therapy takes place once a week throughout the whole 6 intervention months. 121Apart from this, the training program "Obeldicks light" is divided into two phases (see 122 figure 1): In the intensive phase (3 months), the children take part in the nutritional course 123 and in the eating-behaviour course in six group-sessions each lasting for 1.5 hours. At the 124same time, the parents are invited to attend six parents' evenings each lasting 1.5 hours. 125Furthermore, a session of individual nutrition counselling is provided. In the establishing 126phase (three months), one further session of individual nutrition counselling and three 127individual counselling sessions for the child and his/her parents (30 minutes/month) are 128 offered. 
129The exercise therapy consists of trampoline jumping, jogging, ball games, dancing for 130girls, wrestling for boys, and instructions in physical activity as part of every-day life. 131Furthermore, reduction of the amount of time spent watching television or playing 132 computer games is aimed by presenting alternative activity games, which can be played 133 even with few friends without materials under all day circumstances.

134The nutritional teaching is based on the prevention concept of the "Optimized mixed diet". 135In this concept evidence-based recommendations are translated into food-based dietary 136guidelines also considering the dietary habits of children and families in Germany. In 137 contrast to the present-day diet of children in Germany with a fat-content of $38 \%$ of energy 138intake (E\%), $13 \mathrm{E} \%$ proteins, and $49 \mathrm{E} \%$ carbohydrates including $14 \mathrm{E} \%$ sugar, the 139“Optimized mixed diet” is both fat and sugar reduced and contains $30 \mathrm{E} \%$ fat, $15 \mathrm{E} \%$ 140proteins, and $55 \mathrm{E} \%$ carbohydrates including 5 E\% sugar (Reinehr et al. 2010a). The 141 children follow a "traffic-light system" when selecting their food. In this system, the foods 142and drinks available in Germany are separated according to their fat and sugar contents 143into "red = stop", "orange = consider the amount", and "green = o.k. when hungry or 144thirsty".

145The eating behaviour course is predominately behavioural-cognitive but also using 146systemic treatment approaches (Reinehr et al. 2010a): The training is based on behaviour 147 contracts, booster systems, self reflecting curves, impulse control techniques, self 148instructions, cognitive restructuring, development of problem solving strategies, training of 149social competences, model learning via parents and prevention of relapses. One important 150aim of the eating behaviour course is to transfer rigid to flexible eating behaviour. The 151 individual counselling sessions based on systemic and solution-focused theories are aimed 152 to develop concrete solutions to change the family health behaviour consistently tailored to 153 the individual family situation.

154The intervention "Obeldicks light" is offered in two cities (Marl and Datteln) in north-west 155 Germany.

\section{Evaluation of the intervention "Obeldicks light"}

157To prove the effectiveness of the lifestyle intervention "Obeldicks light" we developed an 158 evaluation protocol based on the recommendations of German guidelines for obese 159children and adolescents (www.a-g-a.de/Leitlinie.pdf 2011) and reviews (Ebbeling et al. 1602002; Oude et al. 2009). We decided to perform a study with the best known evidence 161(Ebbeling et al. 2002;Oude et al. 2009), a randomized controlled multi-centre study to 
162prove the effectiveness of the lifestyle intervention for overweight children. Using a 163 computer generated randomization list the children were randomized into an intervention 164group (6 months intervention) or into a control group (waiting period of 6 months). The 165 study was an open randomized controlled trial since blinding was not possible due to the 166nature of the intervention.

167The evaluation design is summarized in table 1 . The primary goal was to reduce 168 overweight and therefore change of weight status was the primary outcome. We decided to 169use the change of standard deviation BMI (BMI-SDS) as change of weight status since 170BMI is gender and age dependent in childhood. The degree of overweight was quantified 171using Cole's least mean square method, which normalized the BMI skewed distribution 172and expressed BMI as a standard deviation score (BMI-SDS) (Cole TJ 1990). Reference 173 data recommended in guidelines for German children were used (Kromeyer-Hauschild K 174et al. 2001; www.a-g-a.de/Leitlinie.pdf 2011). For best available accurate measurements of 175BMI we measured height to the nearest centimetre using a rigid stadiometer and weight 176 was measured unclothed to the nearest $0.1 \mathrm{~kg}$ using a calibrated balance scale.

\section{7-please insert table 1 here-}

1780ne of the secondary aims of the study was to describe the change of body composition. 179The gold standard to determine body composition is DEXA (www.a-g-a.de/Leitlinie.pdf 1802011). However, this measurement is based on X-ray. Therefore we decided to analyze 181body composition by indirect measurements which are well related to DEXA 182measurements (Haroun et al. 2009; Slaughter et al. 1998). We measured skinfold thickness 183 by one investigator at baseline and in follow-up to account for the problem of interpersonal 184 variability which is a relevant confounder of this measurement. To reduce intrapersonal 185 variability triceps and subscapularis skinfold thickness was measured twice using a caliper 186and averaged. The percentage of body fat was calculated with validated formulas (boys: 187 body fat $\%=0.783 \mathrm{x}$ (subscapularis skinfold thickness + triceps skinfold thickness in $\mathrm{mm}$ ) 188+1.6; girls: body fat $\%=0.546 \times$ (subscapularis skinfold thickness + triceps skinfold 189thickness in mm) +9.7) (Slaughter et al. 1998). Furthermore, an additional method of 190determining body composition was used to validate the body composition measurements 191(Haroun et al. 2009): Bioelectrical impedance was measured using leg-leg and hand-leg 192systems (BC418; TANITA, Uxbridge, UK). We used estimates of total body fat, lean body 193mass, and percentage body fat provided by the manufacturer's software based on age, 194gender, height, and weight. No information regarding the formulas used could be obtained 195 from the manufacturer due to its commercially sensitive nature. 
196From a medical point of view an improvement of cardiovascular risk factors is demanded 197in a lifestyle intervention for overweight children. The main cardiovascular risk factors of 1980verweight are central adiposity, hypertension, dyslipidemia, and disturbed glucose 199metabolism in childhood (Ebbeling et al. 2002;www.a-g-a.de/Leitlinie.pdf 2011). Since a 200vein puncture is necessary for the determination of lipids and glucose metabolism, we 201decided to measure blood pressure and waist circumference for body fat distribution to 202keep the expenditure as low as possible for the children in the study. Blood pressure was 203measured by one investigator at baseline and in follow-up to account for the problem of 204interpersonal variability which is a relevant confounder of this measurement. After a 10205 minute rest in the supine position systolic and diastolic blood pressure were measured by 206using a calibrated sphygmomanometer at the right arm according to current guidelines 207(2004) twice and averaged to reduce intrapersonal variability. Furthermore, we determined 208waist circumference, which is highly predictive for cardiovascular risk factors and is a 209measurement of central adiposity (www.a-g-a.de/Leitlinie.pdf 2011). Waist circumference 210was measured by one investigator to account for the problem of interpersonal variability. 211Again, to reduce intrapersonal variability waist circumference was measured twice and 212 averaged.

213From the patient's point of view, improvement of quality of life represents the relevance of 214weight loss since overweight is associated with a reduced quality of life (Wille et al. 2008). $215 \mathrm{We}$ measured the quality of life by the parent and child version of the KINDL® 216questionnaire since all these questionnaires are validated and in use internationally and in 217Germany (Wille et al. 2008). Furthermore, a representative norm sample for Germany 218exists from the KiGGS study (Ravens-Sieberer et al. 2008). The KiGGS study is a German 219national representative study performed in the years 2003-2006 determining health status 220and health behaviour of children (Kurth et al. 2008). The KINDL $\AA$ is a short generic 221 instrument and measures the six dimensions physical well-being, emotional well-being, 222 self-esteem, family, friends and everyday functioning (school) with a total of 24 items. The $223 K I N D L \circledR$ adiposity specific disease module was additionally included in the parent's 224questionnaires as well as in adolescent's questionnaires.

225Understanding which parts of the interventions work and which fail will help to improve 226the lifestyle intervention. For this purpose the kinds of health behaviour was determined as 227 secondary outcome, which are aimed to be changed by the lifestyle intervention. 228Therefore, we decided to measure dietary, eating, exercise, and sedentary behaviour. 229Three-day weighed dietary records were used for the evaluation of dietary intake, which 
230are the best available accurate measurements (Kersting et al. 2005). Furthermore, a 231 representative healthy German cohort was also measured by this method in the DONALD 232study (Sichert-Hellert et al. 2001). The DONALD study is an ongoing representative study 233analyzing the dietary habits of healthy German children (Sichert-Hellert et al. 2001).

234Eating behaviour was assessed by self-report in adolescents by an adapted version of the 235FEV questionnaire (Westenhoefer \& Pudel 21989) which is a German version of the 236Three-Factor-Eating-Questionnaire (Stunkard \& Messick 1985). We used this 237questionnaire since this instrument was evaluated in German children and is used in 238several studies regarding childhood obesity in Germany (Hoffmeister et al. 2010). Only the 239two dimensions dietary restraint and disinhibition were included. Additionally, we 240 measured the habit strength of eating sweets as well as fruits and vegetables by the Self241Report Habit Index (SRHI) (Verplanken \& Orbell 2003) since habit reflects more the 242 stability of eating behaviour than the actual amount of consumed foods. To entrench 243 positive eating habits on the long run is a central goal of nutrition interventions.

244Physical activity and sedentary time were measured by components from different 245 instruments to obtain a comprehensive picture of these complex behaviours. Vigorous 246physical activity was determined by a semi-quantitative questionnaire evaluated in German 247 children in the representative KIGGS study (Lampert et al. 2007a;Kurth et al. 2008). This 248questionnaire measures the frequency of vigorous physical activity not including school 249 sport and exercise training as part of the intervention. The scales were $1=$ never, $2=$ once up 250 to twice per month, $3=$ once up to twice per week, $4=$ three- up to five- times per week, $5=$ 251every day). Additionally parts of the Karlsruhe Activity questionnaire (KAF) (Bös et al. 2522010) were used to measure different every day activities (e.g. transportation to school). 253This questionnaire was also used in the representative KIGGS- study (Kurth et al. 2008). 254Additionally, the habit strength of exercise was measured by the SRHI (Verplanken \& 255Orbell 2003).

256Since the measurement of the exact quantity of physical activity by self-report is limited, 257especially in children (Sallis \& Saelens 2000), physical activity measurement was 258complemented objectively in a sub-sample of children by accelerometers (StepWatch 259Activity Monitor ${ }^{\mathrm{TM}}$ ) for 7 consecutive days before and after the intervention.

260Sedentary time was determined by a questionnaire for children concerning the time for 261television and computer use and other sedentary activities per week (Lampert et al. 2007b), 262Again, this evaluated questionnaire was also integrated in the German representative 
263KIGGS study (Lampert et al. 2007b;Kurth et al. 2008). In addition the SRHI for watching 264TV was employed (Verplanken \& Orbell 2003).

265A final secondary aim was to identify prognostic factors for the effect of the lifestyle 266intervention. Identifying which children will profit from this kind of intervention will help 267to develop tailored interventions. Socio-economic status (SES), ethnicity, and parent BMI 268are known influencing factor on the effectiveness of lifestyle interventions in obese 269children (www.a-g-a.de/Leitlinie.pdf 2011;Oude et al. 2009). Therefore, we measured SES 270of the family by determining the Winkler-index developed for German health surveys 271(Lange et al. 2007) according to the representative KIGGS study (Kurth et al. 2008). This 272 multidimensional index considers parents' education, occupational state, and household 273 income and is separated into 3 groups (low, medium and high). The higher score of mother 274and father was used per household. Children whose parents were both immigrated or of 275non-German citizenship and those who were immigrated themselves and simultaneously $276 \mathrm{had}$ at least one parent of non-German origin were classified as ethnic minorities. All other 277 boys and girls were classified as non-migrants (Schenk et al. 2007). Weight and height of 278parents and siblings were self-reported by the parents and their BMI was calculated.

\section{Study protocol}

280All variables have to be assessed at baseline and the end of intervention or waiting period. 281Since overweight is a chronic disorder all variables have to be measured not only at the end 282of intervention but also at one year follow-up after the end of intervention. To have a 283 conservative estimation of the treatment effect we decided to follow an intention-to-treat 284analysis approach setting all missing values at follow-up due to drop-out back to baseline 285 values.

\section{Sample size calculation for evaluation study}

287Based on a preceding phase-II feasibility cross-over trial in 19 overweight children (at 288baseline $10.7 \pm 2.1$ years, 68\% female, mean BMI-SDS $1.58 \pm 0.19$, mean BMI $22.6 \pm 1.8$ $289 \mathrm{~kg} / \mathrm{m}^{2}$ ) the required sample size for the RCT was estimated (Reinehr et al. 2010c). The 19 290overweight children in the pilot study increased their degree of overweight significantly in 291the six-months waiting period before intervention (mean increase of BMI-SDS $0.15 \pm 0.19$ 292and mean increase of BMI $1.1 \pm 0.9 \mathrm{~kg} / \mathrm{m}^{2}$ ). In the following six-month intervention period, 293by contrast BMI-SDS (mean change $-0.45 \pm 0.21$ ) and BMI (mean change $-1.7 \pm 0.9 \mathrm{~kg} / \mathrm{m}^{2}$ ) 294decreased significantly $(\mathrm{p}<0.001)$. Based on these results and to get a conservative sample 295 size estimate, the mean difference was reduced by $50 \%$ and the standard deviation was 
296increased by 50\% yielding 0.225 as group-difference in BMI-SDS change and 0.315 for its 297 standard deviation. On an alpha $=0.05$ level, two sided tests, a control to intervention ratio 298 of 1 and 80\% power a sample size of 64 (32 per group) was estimated for this study.

\section{Ethical Approval}

300The local ethics committee of the University of Bremen approved this study. Written 301 informed consent is obtained from all subjects and their parents prior to study start.

\section{Results}

\section{Preliminary findings of the intervention "Obeldicks light"}

3040ur first preliminary findings may point towards an effectiveness of the new lifestyle 305 intervention "Obeldicks light" for overweight children and adolescents as well as towards 306the usefulness of our study protocol and the accurateness of our study sample estimation 307(Reinehr et al. 2010c): Our intervention and evaluation protocol was suitable for the 308 participants of the study as demonstrated by a very low drop-out rate $3 \%$ in intervention 309 and $16 \%$ in the control group). Furthermore, we have demonstrated in a previous study that 310our study population did not differ from a general population in Germany concerning 311 social status or ethnicity (Finne et al. 2009) also supporting the generalizability of our 312 results and demonstrating that all social classes were addressed by our intervention. BMI313SDS changes were significantly different across the control and intervention group. In the 314 control group $(n=32)$, BMI increased significantly, while BMI-SDS did not change 315 significantly. In contrast in the intervention group $(n=34)$, BMI and BMI-SDS decreased 316significantly. The success rate defined by reduction of BMI-SDS was $94 \%$ in the 317 intervention group. Given the observed values of the difference and standard deviations of 318BMI-SDS change the power of this study was $>0.999$ at a random error level of 0.05 319(Reinehr et al. 2010c).

320Since the intervention was offered at two different treatment centres, which did not differ 321 in the outcomes of their patients, this finding supports the generalizability of our 322 intervention.

323The reduction of overweight was independent of age and gender of the children (Reinehr 324et al. 2010c) assuming that the materials and methods of the intervention "Obeldicks light" 325are applicable to boys and girls in the age range of 8 to 16 years.

326The achieved reduction of overweight was clinically relevant as demonstrated by a 327 reduction of fat mass both in bioimpedance analyses and skinfold thickness measurements 
328(Reinehr et al. 2010c). Additionally, waist circumference was reduced significantly only in 329the intervention group (Reinehr et al. 2010c). Furthermore, blood pressure decreased 330significantly in the intervention group (Reinehr et al. 2010c).

331A previous study suggests that the reduction of overweight achieved in our lifestyle 332 intervention "Obeldicks light" seems to be caused primarily by changes of dietary patterns 333(Reinehr et al. 2010c): The lifestyle intervention was associated with an improvement of 334dietary patterns (significant reduction of energy (kcal/day), fat and sugar consumption) in 335 the intervention but not in the control group. However, the control and intervention groups 336did not differ in their sports activities and sedentary behaviour suggesting that the 337intervention failed to decrease TV and computer consumption, which is one of the most 338important goal in lifestyle interventions of overweight children (www.a-g339a.de/Leitlinie.pdf 2011; Oude et al. 2009).

340A challenge of our study was the recruitment process in spite of using multiple advertising 341strategies such as newspaper, television, broadcasting, school events, distribution of 342leaflets, and information of family doctors (Finne et al. 2009). Although more than 200 343 families presented for participation during the first 6 months of the recruitment period of 344the evaluation study, this process resulted primarily in the enrolment of obese children, 345 indicating that in the search for overweight children, predominantly obese children felt 346addressed and the subjective need for lifestyle intervention for overweight children seems 347to be low (Finne et al. 2009).

\section{Conclusions}

350This paper describes the development of a lifestyle intervention for overweight children as 351 well as its evaluation design. Our findings will probably help to implement other lifestyle 352interventions in different regions.

353Our evaluation protocol was suitable for the participants of study as demonstrated by a 354very low drop-out rate and addressing all social classes. However, our study protocol has a 355 few important potential limitations. Since physical activity training, behaviour counselling, 356and nutritional education were performed simultaneously in the intervention group, we 357 cannot distinguish the impact of each of them on overweight reduction. Furthermore, the 358 effects of dieting and increased physical activity probably strengthened each other. Self359reported data were used to measure dietary habits and physical activity and it can be 360 questioned as to what extent they reflect the real habits. Underreporting is a well-known 
361 phenomenon in overweight and obese subjects (Ebbeling et al. 2002). Therefore, 362 conclusions based on self-reported data such as dietary records and questionnaires have to 363 be drawn very cautiously. However, objective measurements such as accelerometry will 364help us to interpret the findings.

365Reducing the treatment intensity of well-established lifestyle interventions for obese 366 children was a simple way to develop a lifestyle intervention for overweight children. The 367advantages are that the methods to achieve a change of lifestyle habits are well-established 368as well as the therapists are familiar with the implementation (as they are already 369experienced in "Obeldicks" training).

370The achieved reduction of overweight at the end of the lifestyle intervention "Obeldicks 371light" was comparable to effects of lifestyle intervention in obese children (Reinehr et al. 3722010b;Oude et al. 2009). This finding seems remarkable since only 50\% of the physical 373activity lessons as well as time- and cost-intensive individual counselling were used in 374“"Obeldicks light" as compared to the lifestyle intervention "Obeldicks" for obese children. 375Furthermore, the success rate in our study was much higher as compared to these studies in 376obese children using much more intensive interventions suggesting that an early 377 intervention in overweight, but not obese children is preferable.

378However, for the final conclusion of an effectiveness of our new lifestyle intervention 379 “Obeldicks light", we have to wait for the end of the follow-up study to prove whether the 380achieved weight loss was sustained. Furthermore, ongoing studies analyzing the changes of 381 quality of life will help us to verify that the achieved weight reduction is also relevant for 382the patients. Additionally, identification of predictive factors for success in ongoing studies 383 will help to determine which children will have the greatest profit of this kind of 384intervention probably influencing our inclusion criteria. 
392Conflict of interest:

393All authors have no conflict of interest

394

395

396Acknowledgements

397AS, TR and KW developed the lifestyle intervention, TR, EF and PK performed the 398evaluation study, AS, KW, EF, PK and TR performed the discussion, TR wrote the first 399version of the manuscript

400

401The "Obeldicks light" intervention was initiated by the health insurances Techniker 402Krankenkasse (TK), Kaufmänische Krankenkasse / Allianz (KKH Allianz), Deutsche 403Angestellten Krankenkassen (DAK), and the Vestische Kinder- und Jugendklinik Datteln.

404This study was funded by the German Federal Ministry of Research (grant numbers 40501EL619 and 01EL0603)

406

407

408

409

410

411

412

413

414

415

416

417

418

419

420

421

422

423

424

425

426

427

428

429

430

431

432

433

434

435

436

437

438 
441Anonymous (2004) The fourth report on the diagnosis, evaluation, and treatment of high 442 blood pressure in children and adolescents. Pediatrics, 114, 555-576

443Baker JL, Olsen LW, Sorensen TI (2007) Childhood body-mass index and the risk of 444coronary heart disease in adulthood. $N$ Engl J Med 357:2329-2337

445Biro FM, Wien M (2010) Childhood obesity and adult morbidities. Am J Clin Nutr 44691:1499S-1505S

447Bös K, Heel J, Romahn N, Tittlbach SWAWT (2010) Untersuchungen zur Motorik im 448Rahmen des Kinder- und Jugendsurveys. Gesundheitswesen 64:80-87

449Cole TJ (1990) The LMS method for constructing normalized growth standards. Eur $J$ 450Clin Nutr 44:45-60

451Ebbeling CB, Pawlak DB, Ludwig DS (2002) Childhood obesity: public-health crisis, 452common sense cure. Lancet 360:473-482

453Finne E, Reinehr T, SchaeferA, Winkel K, Kolip P (2009) Overweight children and 454adolescents--is there a subjective need for treatment? Int J Public Health 54:112-116

455Flodmark CE (2005) Management of the obese child using psychological-based 456treatments. Acta Paediatr Suppl 94:14-22

457Haroun D, Croker H, Viner RM, Williams JE, Darch TS, Fewtrell MS, Eaton S, Wells JC 458(2009) Validation of BIA in Obese Children and Adolescents and Re-evaluation in a 459Longitudinal Study. Obesity (Silver Spring) 17:2245-2250

460Hoffmeister U, Bullinger M, van Egmond-Fröhlich A, Goldapp C, Mann R, Ravens461Sieberer U, Reinehr T, Westenhöfer J, Wille N, Holl R (2010) Übergewicht und Adipositas 462in Kindheit und Jugend: Evaluation der ambulanten und stationären Versorgung in 463Deutschland in der „EvAKuJ-Studie". Bundesgesundheitsblatt Gesundheitsforschung 464Gesundheitsschutz, in press

465http: www.a-g-a.de/Leitlinie.pdf. Guidelines of the German working group on obese 466children and adolescents. 2011. Accessed 28 February 2011

467I'Allemand D, Wiegand S, Reinehr T, Muller J, Wabitsch M, Widhalm K, Holl R (2008) 468Cardiovascular risk in 26,008 European overweight children as established by a 469multicenter database. Obesity (Silver Spring) 16:1672-1679

470Kersting M, Alexy U, Clausen K (2005) Using the concept of Food Based Dietary 471 Guidelines to Develop an Optimized Mixed Diet (OMD) for German children and 472adolescents. J Pediatr Gastroenterol Nutr 40:301-308

473Kromeyer-Hauschild K, Wabitsch M, Geller F, Ziegler A, Geiss HC, Hesse V, von Hippel 474V, Jäger U, Johnson D, Korte W, Kunze D, Menner K, Müller G, Müller M, Niemann475Pilatus A, Remer T, Schäfer F, Wittchen H, Zabransky S, Zelnner K, Hebebrand J (2001) 476Percentiles of body mass index in children and adolescents evaluated from different 477regional German studies. Monatsschr Kinderheilkd 149:807-818 
478Kurth BM, Kamtsiuris P, Holling H, Schlaud M, Dolle R, Ellert U, Kahl H, Knopf H, 479Lange M, Mensink GB, Neuhauser H, Rosario AS, Scheidt-Nave C, Schenk L, Schlack R, 480Stolzenberg H, Thamm M, Thierfelder W, Wolf U (2008) The challenge of 481 comprehensively mapping children's health in a nation-wide health survey: design of the 482German KiGGS-Study. BMC Public Health 8:196

483Lampert T, Mensink GB, Romahn N, Woll A (2007a) Physical activity among children 484and adolescents in Germany. Results of the German Health Interview and Examination 485Survey for Children and Adolescents (KiGGS). Bundesgesundheitsblatt 486Gesundheitsforschung Gesundheitsschutz 50:634-642

487Lampert T, Sygusch R, Schlack R (2007b) Use of electronic media in adolescence. Results 488of the German Health Interview and Examination Survey for Children and Adolescents 489(KiGGS). Bundesgesundheitsblatt. Gesundheitsforschung. Gesundheitsschutz 50:643-652

490Lange M, Kamtsiuris P, Lange C, Schaffrat Rosario A, Stolzenberg H, Lampert T (2007) 491Sociodemographic characteristics in the German Health Interview and Examination Survey 492 for Children and Adolescents (KiGGS) - operationalisation and public health significance, 493taking as an example the assessment of general state of health. Bundesgesundheitsblatt 49450:578-589

495Lorenz MW, Markus HS, Bots ML, Rosvall M, Sitzer M (2007) Prediction of clinical 496cardiovascular events with carotid intima-media thickness: a systematic review and meta497analysis. Circulation 115:459-467

498Monasta L, Batty GD, Macaluso A, Ronfani L, Lutje V, Bavcar A, van Lenthe FJ, Brug J, 499Cattaneo A (2010) Interventions for the prevention of overweight and obesity in preschool 500children: a systematic review of randomized controlled trials. Obes Rev

501DOI:10.1111/j.1467-789X.2010.00774.x. Accessed 22 JUN 2010

502Oude LH, Baur L, Jansen H, Shrewsbury VA, O'Malley C, Stolk RP, Summerbell CD 503(2009) Interventions for treating obesity in children. Cochrane Database Syst Rev $504 \mathrm{CD} 001872$

505Ravens-Sieberer U, Erhart M, Wille N, Bullinger M (2008) Health-related quality of life in 506children and adolescents in Germany: results of the BELLA study. Eur Child Adolesc 507Psychiatry 17 Suppl 1:148-156

508Reinehr T, Dobe M, Kersting M (2010a) Therapie der Adipositas im Kindes- und 509Jugendalter: Schulung Obeldicks und Obeldicks Light. 2. Auflage edn Hogrefe Verlag

510Reinehr T, Andler W, Denzer C, Siegried W, Mayer H, Wabitsch M (2005a)

511Cardiovascular risk factors in overweight German children and adolescents: relation to 512gender, age and degree of overweight. Nutr Metab Cardiovasc Dis 15: 181-187

513Reinehr T, de Sousa G, Toschke AM, \& Andler W (2006) Long-term follow-up of 514 cardiovascular disease risk factors in children after an obesity intervention. Am J Clin Nutr $51584: 490-496$

516Reinehr T, Kersting M, Wollenhaupt A, Alexy U, Kling B, Strobele K, Andler W (2005b) 517Evaluation of the training program "OBELDICKS" for obese children and adolescents. 518Klin Padiatr 217:1-8 
519Reinehr T, Kleber M, Lass N, Toschke AM (2010b) Body mass index patterns over 5 y in 520obese children motivated to participate in a 1-y lifestyle intervention: age as a predictor of 521long-term success. Am. J Clin Nutr 91:1165-1171

522Reinehr T, Schaefer A, Winkel K, Finne E, Toschke AM, Kolip P (2010c) An effective 523lifestyle intervention in overweight children: findings from a randomized controlled trial 524on "Obeldicks light". Clin Nutr 29:331-336

525Sallis J, Saelens B (2000) Assessment of physical activity by self-report: status, 526limitations, and future directions. Research Quarterly for Exercise and Sport 71:1-14

527Schenk L, Ellert U, Neuhauser H (2007) Kinder und Jugendliche mit 528Migrationshintergrund in Deutschland. Bundesgesundheitsblatt 50:590-599

529Sichert-Hellert W, Kersting M, Manz F (2001) Changes in time-trends of nutrient intake 530 from fortified and non-fortified food in German children and adolescents--15 year results 531 of the DONALD study. Dortmund Nutritional and Anthropometric Longitudinally 532Designed Study. Eur J Nutr 40:49-55

533Slaughter M, Lohmann T, Boileau R, Horswill C, Stillmann R, Bemben D (1998) Skinfold 534equations for estimation of body fatness in children and youth. Hum Biol 60:709-723

535Stunkard AJ, Messick S (1985) The three-factor eating questionnaire to measure dietary 536restraint, disinhibition and hunger. J Psychosom Res 29:71-83

537Verplanken B, Orbell S (2003) Reflections on past behavior: A self-report index of habit 538strength. Journal of Applied Social Psychology 33:1313-1330

539WestenhoeferJ, Pudel V (1989) Fragebogen zum Eßverhalten (FEV). Handanweisung. 540Hogrefe

541Wille,N., Erhart,M., Petersen,C., \& Ravens-Sieberer,U. (2008) The impact of overweight 542and obesity on health-related quality of life in childhood--results from an intervention 543study. BMC Public Health 8:421

544Wunsch R, de Sousa G, Toschke AM, Reinehr T (2006) Intima-media thickness in obese 545children before and after weight loss. Pediatrics 118:2334-2340

546

547

548

549

550

551

552

553

554

555Table 1: Design of the evaluation study 
556

557

558

Design: Randomized controlled trial with intention-to treat analyses and measurements at

- baseline,

$\bigcirc$ end of intervention or end of waiting period, and

- 1 year after end of intervention

- Measurements:

Primary outcome: change of BMI-SDS

○ Secondary outcome:

- change of body composition (bioimpedence analysis, skinfold measurements)

- change of cardiovascular risk factors (waist circumference, blood pressure)

- change of quality of life (questionnaire (Ravens-Sieberer et al. 2008))

- change of health behaviour

three-day-weighed dietary records

eating habits (questionnaire (Verplanken \& Orbell 2003; Westenhoefer \& Pudel 21989))

exercise habits (questionnaire (Verplanken \& Orbell 2003;Lampert et al. 2007a;Lampert et al. 2007b;Bös et al. 2010))

- sedentary behaviour (questionnaire (Verplanken \& Orbell 2003))

$\bigcirc$ accelerometer measurements 
583Figure 1: Structure of the lifestyle intervention "Obeldicks" for obese children and 584"Obeldicks light" for overweight children, the dashed vertical line divided the intervention 585 period into two 3-month subunits 
outpatient lifestyle intervention "Obeldicks" for obese children

„Obeldicks light" for overweight children

Nutrition, physical exercise and behavior education

Behavior counseling

Nutrition

education parent + child

parents group

children groups

Individual counseling for

the child and his/her family

Physical activity training establishing phase
Nutrition, physical exercise

and behavior education

Behavior

counseling
Nutrition

education

\section{Physical activity training}

Intensive phase establishing phase
Individual counseling for

the child and his/her family

$\longleftarrow$ 